\title{
Biorreguladores em feijoeiro cultivado sob dois regimes hídricos
}

\author{
Plant bioregulators on common bean cultivated under two soil moisture
}

\author{
Miller Henrique Ferreira ${ }^{1}$, Danúbia Aparecida Costa Nobre ${ }^{2}$, Willian Rodrigues Macedo ${ }^{1 *}$ \\ 1Universidade Federal de Viçosa, Viçosa, MG, Brasil. *Autor para correspondência: willian_rmacedo@yahoo.com.br. \\ ${ }^{2}$ Universidade Federal dos Vales do Jequitinhonha e Mucuri, Diamantina, MG, Brasil.
}

Submissão: 29/03/2019 / Aceite: 10/12/2019

\begin{abstract}
RESUMO
Restrições na disponibilidade hídrica favorecem eventuais danos à cultura do feijoeiro, e o uso de biorreguladores aprimora a sinalização vegetal e potencializa a indução de tolerância ao déficit hídrico. Este estudo objetivou caracterizar alterações fisiológicas, bioquímicas e biométricas em plantas de feijão submetidas à aplicação foliar de biorreguladores sob diferentes regimes hídricos. $O$ ensaio consistiu na aplicação de um controle (água) e três biorreguladores ( $5 \mu \mathrm{M}$ de ácido abscísico - ABA; $50 \mu \mathrm{M}$ de metil jasmonato - MeJA e $5 \mu \mathrm{M}$ de ABA + $50 \mu \mathrm{M}$ de MeJA), além de apresentar dois regimes hídricos (60 e $80 \%$ da capacidade de campo), num esquema fatorial $4 \times 2$. Foram analisados: conteúdo de pigmentos fotossintetizantes, trocas gasosas foliares e índices biométricos das plantas de feijoeiro. Com resultado observou-se que o tratamento $A B A+M e J A$ incrementou a concentração de clorofila $b$, atividades de ascorbato peroxidase (APX) e catalase (CAT), enquanto a taxa fotossintética foi estimulada pela mistura de biorreguladores aos 36 dias após o plantio (DAP), ABA e MeJA, isolados, propiciaram maior taxa fotossintética no feijoeiro aos 34 DAP, enquanto para as variáveis biométricas somente foram influenciadas pelos regimes hídricos, com relação aos mecanismos bioquímicos, constatou-se que o tratamento $A B A+M e J A$ incrementou a atividade das enzimas antioxidantes e melhorou as respostas de trocas gasosas em condição de menor disponibilidade hídrica. Os biorreguladores avaliados nesta pesquisa são benéficos na modulação da fisiologia vegetal em plantas sob estresse hídrico, entretanto o suprimento de água adequado retrata um melhor desenvolvimento das plantas.
\end{abstract}

PALAVRAS-CHAVE: ácido abscísico, metil jasmonato, agricultura tropical, déficit hídrico.

\begin{abstract}
Restrictions on water available lead to possible damages in the bean crop, and the use of bioregulators can improve the plant signal and boost tolerance against drought stress. This study aimed to characterize physiological, biochemical, and biometric alterations in bean plants subjected to foliar application of bioregulators under different soil water levels. The following treatments were applied: control (water) and three bioregulators $(5 \mu \mathrm{M}$ of abscisic acid - ABA, $50 \mu \mathrm{M}$ of methyl jasmonate - MeJA, and $5 \mu \mathrm{M}$ of ABA + $50 \mu \mathrm{M}$ of MeJA). Also, the plants were subjected to two soil water levels (60 and $80 \%$ of field capacity), in a $4 \times 2$ factorial scheme. The variables studied were: content of photosynthetic pigments, leaf gas exchange, and biometric indexes in the common bean plants. Our results showed that the ABA + MeJA treatment increased the concentration of chlorophyll $b$, ascorbate peroxidase (APX), and catalase (CAT) activities. At the same time, the photosynthetic rate was stimulated by the mixture of bioregulators on 36 days of planting (DAP). ABA and MeJA, applied isolated, caused a higher photosynthetic rate in the bean in the 34 DAP, whereas for the biometric variables, they were only influenced by the soil water levels. Regarding the biochemical mechanisms, it was verified that the ABA + MeJA treatment increased the activity of antioxidant enzymes and improved gas exchange responses in a condition of lower water availability. The bioregulators assessed in this research are beneficial in the modulation of plant physiology in plants under drought stress. However, the adequate water supply represents a better development of the plants.
\end{abstract}

KEYWORDS: abscisic acid, methyl jasmonate, tropical agriculture, drought stress.

\section{INTRODUÇÃO}

O estresse hídrico apresenta grande amplitude de ocorrência nas áreas agrícolas do mundo (MUÑOZ-PEREA et al. 2006), com efeitos mais intensos sobre a fotossíntese, o crescimento e a 
produtividade das plantas (ZLATEV \& LIDON 2012). Em um cenário atual projeta-se a necessidade de aumentar em $70 \%$ a produção de alimentos, para atender a futura demanda mundial, sendo necessário buscar novas técnicas de manejo e tecnologias que proporcionem maior uso eficiente da água e fertilizantes, de processos produtivos para produção de alimentos e da redução dos impactos negativos que a agricultura causa ao ambiente (GRAFTON et al. 2015, RAHMAN 2016).

Os biorreguladores são moléculas orgânicas que promovem ou inibem o crescimento e desenvolvimento vegetal, atuando na divisão e crescimento celular, padrões de formação, florescimento, frutificação e formação de sementes (GIANNAKOULA et al. 2012), podendo promover maiores rendimentos das plantas cultiváveis, através da amenização de estresses abióticos, assim como estimulando o desenvolvimento das plantas e, consequentemente, seus índices produtivos (RATNAKUMAR et al. 2016). Dentre as novas classes de biorreguladores com potencial aplicabilidade a agricultura destacam-se: 0 ácido abscísico (ABA) importante molécula mediadora dos mecanismos de defesa, promovendo tolerância a estresses induzidos por seca, salinidade, ozônio e baixa temperatura (BARI \& JONES 2009), e o metil jasmonato (MeJA) e ácido jasmônico (AJ), pertencentes ao grupo dos jasmonatos, moléculas com importantes funções na regulação celular, germinação de sementes, crescimento radicular, fertilidade das flores, amadurecimento de frutos e senescência da planta (WASTERNACK \& HAUSE 2002).

Informações prévia sobre mecanismos de ação do ABA e MeJA indicam que essas moléculas promovem maior uso eficiente de água das plantas (YANG et al. 2016), aumento da concentração de enzimas antioxidantes (SOARES et al. 2010, CHOUDHARY et al. 2012), aumento na concentração de pigmentos foliares e carotenoides (SANKAR et al. 2013), o que os qualifica como uma importante ferramenta na proteção vegetal e no incremento da produtividade. Especificamente para o feijoeiro, o uso exógeno do ABA foi essencial para a mitigação do estresse salino (KHADRI et al. 2006), enquanto o MeJA está envolvido em indução de respostas de defesa e tolerância à doenças (OLIVEIRA et al. 2015).

No Brasil das três épocas recomendadas ao cultivo do feijoeiro, duas estão sujeitas a condições de seca (LANNA et al. 2016), o que demanda um manejo mais cauteloso por parte do produtor rural, para a obtenção de todo o potencial genético das plantas. Assim este trabalho objetivou caracterizar alterações fisiológicas, bioquímicas e biométricas em plantas de feijão em função da aplicação foliar de ácido abscísico e metil jasmonato, em plantas condicionadas a dois níveis de água no solo.

\section{MATERIAL E MÉTODOS}

O experimento foi conduzido em casa de vegetação na área experimental da Universidade Federal de Viçosa, Campus de Rio Paranaíba. A temperatura mínima registrada durante o período de imposição dos tratamentos até o final da condução do experimento foi de $18{ }^{\circ} \mathrm{C}$ e a máxima de $41^{\circ} \mathrm{C}$. Os tratamentos foram compostos da combinação de dois fatores: biorreguladores e regime hídrico. $O$ fator biorreguladores foi constituído por água (controle); $5 \mu \mathrm{M}$ de ABA; $50 \mu \mathrm{M}$ de MeJA; e $5 \mu \mathrm{M}$ de ABA + $50 \mu \mathrm{M}$ de MeJA, enquanto o fator regime hídrico foi constituído por 60 e $80 \%$ da capacidade de campo (CC). Em esquema fatorial $4 \times 2$ (quatro fontes de biorreguladores e dois níveis de água no solo), em delineamento inteiramente casualizado. Com três repetições $(n=3)$ para análise das enzimas antioxidantes e quatro repetições $(n=4)$ para as variáveis de trocas gasosas e biometria.

Cada unidade experimental foi formada por um vaso de $5 \mathrm{dm}^{-3}$. Os vasos foram preenchidos com Latossolo Vermelho com as seguintes características químicas: $\mathrm{pH} \mathrm{H}_{2} \mathrm{O}: 6,0 ; \mathrm{P}$ (Mehlich 1): $2 \mathrm{mg} \mathrm{dm}^{-3}$; $\mathrm{P}$ (rem): $3,5 \mathrm{mg} \mathrm{L}^{-1} ; \mathrm{K}: 0,03 \mathrm{cmolc} \mathrm{dm}^{-3}$; Ca: $2,2 \mathrm{cmolc} \mathrm{dm}^{-3}$; Mg: $0,4 \mathrm{cmolc} \mathrm{dm}^{-3}$; Al: $0,0 \mathrm{cmolc} \mathrm{dm}^{-3} ; \mathrm{H}+\mathrm{Al}: 3,7$ cmolc $\mathrm{dm}^{-3}$; M.O: $32 \mathrm{~g} \mathrm{dm}^{-3}$.

As sementes da cultivar BRS Pérola foram previamente tratadas com o inseticida thiamethoxam na dose de $250 \mathrm{~mL}$ por $100 \mathrm{~kg}$ de semente, e em cada vaso cultivaram-se seis sementes, após a emergência ocorreu o desbaste das plantas, remanescendo uma por vaso, sendo essas irrigadas diariamente ao nível de $80 \%$ da CC, até o momento da imposição dos tratamentos.

Quando as plantas se encontravam no estádio de desenvolvimento $\mathrm{V} 4$, aos 33 dias após a semeadura (DAS), foram estabelecidos os tratamentos dos biorreguladores e níveis de estresse hídrico. Os biorreguladores foram diluídos em solução aquosa, com adição de $0,1 \%$ surfactante não iônico (poliéterpolimetil siloxano), e sua aplicação se deu via pulverizador manual, de capacidade de $1 \mathrm{~L}$ e pressão máxima de $300 \mathrm{kPa}$, sendo as plantas aspergidas em sua face adaxial até o ponto de escorrimento superficial. Enquanto para controlar os níveis de estresse adotamos a metodologia de pesagem dos vasos, com auxílio de uma balança eletrônica foram realizadas aferições diárias do conteúdo de água no solo, tendo a irrigação com água até o ponto dos regimes hídricos estabelecidos, durante oito dias. A determinação da capacidade de campo foi realizada em laboratório através do método da pesagem (FERNANDES \& SYKES 1968), para 
obtenção da capacidade de campo do solo, expressos em porcentagem (\%).

A aplicação dos biorreguladores foi realizada em dois momentos, o primeiro concomitante ao estabelecimento dos distintos níveis de suprimento de água no solo (34 DAS), e a segunda aplicação 30 horas após a primeira (36 DAS).

Aos oito dias após a primeira aplicação dos biorreguladores foi coletada uma folha, oriunda do terço médio da planta, em seguida esta foi acondicionada em caixa de isopor contendo gelo e levada para laboratório onde se conduziram as análises bioquímicas. O material foi pulverizado em nitrogênio líquido, com auxílio de almofariz, para obtenção do extrato vegetal que foi utilizado nas análises de: atividade de superóxido dismutase (SOD, EC 1.15.1.1), atividade de ascorbato peroxidase (APX, EC: 1.11.1.11) e atividade de catalase (CAT, EC 1.11.1.6).

A determinação dos teores de proteínas totais solúveis (PTS) consistiu na maceração das folhas em tampão Tris- $\mathrm{HCl}, 50 \mathrm{mM}$, pH 7,5, posteriormente se procedeu a reação com o reagente de Bradford (LGC Biotecnologia, Cotia, SP, Brasil), os resultados obtidos foram expressos em $\mathrm{mg}$ de proteína por $\mathrm{g}^{-1}$ de matéria fresca (BRADFORD 1976).

A atividade da SOD foi determinada pela adição de $100 \mu \mathrm{L}$ de extrato enzimático, a $1880 \mu \mathrm{L}$ de uma

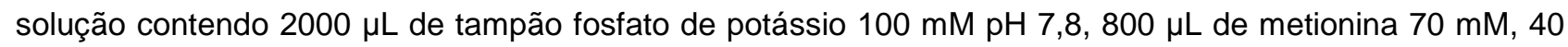
$\mu \mathrm{L}$ de EDTA $10 \mu \mathrm{M}, 300 \mu \mathrm{L}$ de NBT $1 \mathrm{mM}$ e $620 \mu \mathrm{L}$ de $\mathrm{H}_{2} \mathrm{O}$ Milli-Q. A reação ocorreu em uma câmara, sob iluminação de lâmpadas fluorescente de $15 \mathrm{~W}$, com exposição de 10 minutos. As amostras foram levadas ao espectrofotômetro UV-Vis para leitura em comprimento de onda de $560 \mathrm{~nm}$. Uma unidade da enzima (UA) foi definida como a quantidade de enzima necessária para inibir, em $50 \%$, a fotorredução do NBT (BEAUCHAMP \& FRIDOVICH 1971, GIANNOPOLITIS \& RIES 1977).

Para determinação da CAT, uma alíquota de $12,5 \mu \mathrm{L}$ do extrato enzimático foi adicionado a $500 \mu \mathrm{L}$ de tampão fosfato de potássio $200 \mathrm{mM}, \mathrm{pH} 7,0$ e $400 \mu \mathrm{L}$ de $\mathrm{H}_{2} \mathrm{O}$ Milli-Q à $27^{\circ} \mathrm{C}$ e ainda, $50 \mu \mathrm{L}$ de $250 \mathrm{mM}$ de $\mathrm{H}_{2} \mathrm{O}_{2}$ e $37,5 \mu \mathrm{L}$ de $\mathrm{H}_{2} \mathrm{O}$. Onde a atividade da enzima foi determinada pela mensuração da redução na absorbância das amostras a $240 \mathrm{~nm}$, em decorrência do consumo do $\mathrm{H}_{2} \mathrm{O}_{2}$ (HAVIR \& MCHALE 1987, ANDERSON et al. 1995).

A atividade da APX foi realizada tomando-se uma alíquota de $12,5 \mu \mathrm{L}$ do extrato enzimático, a qual foi

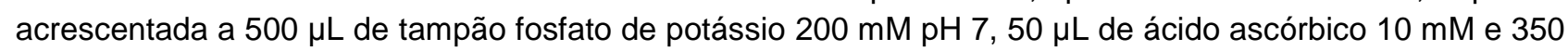
$\mu \mathrm{L}$ de $\mathrm{H}_{2} \mathrm{O}$ Milli-Q à $27^{\circ} \mathrm{C}$ e ainda, $50 \mu \mathrm{L}$ de $\mathrm{H}_{2} \mathrm{O}_{2}(2 \mathrm{mM})$ e $37,5 \mu \mathrm{L}$ de $\mathrm{H}_{2} \mathrm{O}$. O decréscimo na absorbância a $290 \mathrm{~nm}$ foi medido durante um minuto, de $10 \mathrm{em} 10$ segundos. A atividade enzimática foi calculada utilizando-se o coeficiente de extinção molar de $2,8 \mathrm{mM}^{-1} \mathrm{~cm}^{-1}$ (NAKANO \& ASADA 1981).

Para a análise de pigmentos foliares foi seguido o procedimento de MACEDO et al. (2013), por meio de um extrator ( $80 \%$ acetona) sem o processo de maceração dos tecidos vegetais, com posterior leitura em espectrofotômetro nos comprimentos de onda de: 470, 645, e $663 \mathrm{~nm}$ para as clorofilas a, b e total (WITHAM et al. 1971), e de $470 \mathrm{~nm}$ para os carotenóides (LICHTENTHALER \& WELLBURN 1983), os resultados foram expressos em miligrama do pigmento por grama de peso fresco de tecido foliar $\left(\mathrm{mg} \mathrm{g}^{-1}\right)$.

Foram mensuradas ainda a altura de plantas $(A P, c m)$ e número de botões florais (BF Planta ${ }^{-1}$ ) no quinto dia após o início da imposição dos tratamentos. Enquanto o conteúdo relativo de água (CRA) das folhas foi aferido coletando-se amostras padronizadas $(4 \times 4 \mathrm{~cm})$ das folhas do terço médio de cada planta, no oitavo dia após a imposição dos tratamentos. Estas amostras foram pesadas individualmente para obtenção do peso fresco, logo após, as amostras foram colocadas em água durante 24 horas e pesadas novamente para a obtenção do peso úmido. Então, as amostras foram levadas para estufa de circulação forçada de ar por 72 horas a $70^{\circ} \mathrm{C}$ e posteriormente pesadas para obtenção do peso seco. Os valores foram expressos em percentagem, onde foi feito o cálculo do CRA a partir da formula:

$$
C R A=\frac{\text { PF }- \text { PS }}{\text { PU - PS }} \times 100
$$

Onde: $\mathrm{PF}=$ peso fresco do tecido; $\mathrm{PS}=$ peso seco do tecido; $\mathrm{PU}=$ peso úmido do tecido.

As análises fotossintéticas consistiram de: taxa fotossintética $\left(A-\mu \mathrm{mol} \mathrm{m}^{-2} \mathrm{~s}^{-1}\right)$; condutância estomática $\left(g s-\mathrm{mol} \mathrm{m}^{-1} \mathrm{~s}^{-1}\right)$, transpiração $\left(E-\mathrm{mol} \mathrm{H}_{2} \mathrm{O} \mathrm{m}^{-2} \mathrm{~s}^{-1}\right)$, concentração intracelular de $\mathrm{CO}_{2}(\mathrm{Ci}-\mu \mathrm{mol}$ $\left.\mathrm{mol}^{-1}\right)$ e uso eficiente de água $(A / E)$, num período compreendido entre 8:30 e 11:30 horas, sob radiação fotossinteticamente ativa de $1200 \mu \mathrm{mol}$ fótons $\mathrm{m}^{-2} \mathrm{~s}^{-1}$, com auxílio de um analisador de gás infravermelho (IRGA) modelo LI-6400XT (LI-COR, Lincoln, Nebraska, USA), acoplado a uma fonte luminosa artificial (6400-02B, LI-COR Biosciences, USA). Foram realizadas duas análises de trocas gasosas, a primeira 24 horas após a imposição dos tratamentos e a segunda 12 horas após a reaplicação dos tratamentos, ou seja, 36 horas após a imposição dos tratamentos. 
Os dados foram submetidos a análise de variância (ANOVA) e as médias foram comparadas pelo teste de Tukey a 5\%. O programa utilizado foi o software $R$ versão 3.3.1. Utilizaram-se três repetições $(n=3)$ para os dados de enzimas antioxidantes, e quatro repetições $(n=4)$ para as demais variáveis analisadas.

\section{RESULTADOS E DISCUSSÃO}

Tendo em vista o efeito dos fatores analisados sobre as plantas de feijoeiro, não observamos respostas deletérias promovidas pelo uso dos biorreguladores ou pela restrição hídrica às plantas para o conteúdo de clorofila a, clorofila total e carotenoides (Tabela 1). O estresse hídrico afeta negativamente a presença dos pigmentos fotossintéticos (JALEEL et al. 2009), tornando-os adequados indicadores fisiológicos nas plantas (PAVLOVIĆ et al. 2014). Portanto nossos resultados apontam que a restrição hídrica de $60 \%$ da CC não representou uma condição drástica para a cultura do feijoeiro.

Em contrapartida observamos que houve interação significativa entre os biorreguladores e o nível de água no solo para a variável clorofila $b$, o tratamento ABA+MeJA, ao nível de $60 \%$ da CC, promoveu incrementos no conteúdo deste pigmento, e entre os níveis de água no solo o tratamento com $5,0 \mu \mathrm{M}$ de ABA em plantas sob condição de estresse reduziu o conteúdo de clorofila $b$ (Tabela 1 ).

Tabela 1. Conteúdo de clorofila $a, b$, total e carotenoides $\left(\mathrm{mg} \mathrm{g}^{-1}\right)$ em folhas plantas de feijão tratadas com biorreguladores em dois níveis de água no solo.

Table1. Content of chlorophyll a, b, total, and carotenoids $\left(\mathrm{mg} \mathrm{g}^{-1}\right)$ in common bean leaves, treated with bioregulators and subjected to two water levels in the soil.

\begin{tabular}{|c|c|c|c|}
\hline Biorreguladores & Clorofila a & Clorofila Total & Carotenoides \\
\hline Controle & $1,86( \pm 0,2) a^{\star}$ & $2,82( \pm 0,1) a$ & $0,06( \pm 0,005) \mathrm{a}$ \\
\hline ABA & $1,78( \pm 0,2) a$ & $2,44( \pm 0,2) a$ & $0,06( \pm 0,004) a$ \\
\hline MeJA & $1,84( \pm 0,1) \mathrm{a}$ & $2,48( \pm 0,1) a$ & $0,06( \pm 0,003) a$ \\
\hline$A B A+M e J A$ & $1,68( \pm 0,2) a$ & $2,67( \pm 0,1) \mathrm{a}$ & $0,06( \pm 0,006) \mathrm{a}$ \\
\hline \multicolumn{4}{|c|}{ Níveis de Água no Solo } \\
\hline $60 \%$ & $1,68( \pm 0,1) a$ & $2,47( \pm 0,1) a$ & $0,06( \pm 0,003) \mathrm{a}$ \\
\hline $80 \%$ & $1,90( \pm 0,1) a$ & $2,74( \pm 0,1) a$ & $0,07( \pm 0,004) a$ \\
\hline $\mathrm{CV}(\%)$ & 30,9 & 17,1 & 21,9 \\
\hline Tratamentos & \multicolumn{3}{|c|}{ Níveis de água no solo } \\
\hline & \multicolumn{2}{|c|}{$60 \%$} & $80 \%$ \\
\hline Controle & \multicolumn{2}{|c|}{$0,64( \pm 0,07) \mathrm{bA}$} & $0,84( \pm 0,10) \mathrm{aA}$ \\
\hline ABA & \multicolumn{2}{|c|}{$0,55( \pm 0,04) b B$} & $0,77( \pm 0,06)$ aA \\
\hline MeJA & \multicolumn{2}{|c|}{$0,56( \pm 0,03) b A$} & $0,70( \pm 0,04)$ aA \\
\hline$A B A+M e J A$ & \multicolumn{2}{|c|}{$0,93( \pm 0,09)$ aA } & $0,85( \pm 0,09)$ aA \\
\hline $\mathrm{CV}(\%)$ & \multicolumn{3}{|c|}{21,2} \\
\hline
\end{tabular}

A clorofila $b$ apresenta função primordial no tamanho do complexo antena e sua biossíntese está diretamente relacionada a eficiência da fotossíntese (OSTER et al. 2000), os resultados apontam que a interação $A B A+M e J A$ incrementou o conteúdo deste pigmento em feijão sob baixa disponibilidade hídrica. Ponderamos que a rota biossíntética dos pigmentos clorofilados possui rota em comum com o $A B A$, a via do metil-eritritrol-fosfato (BARICKMAN et al. 2014), assim este biorregulador induziu uma regulação positiva sobre este pigmento, além disso, o MeJA é capaz de realizar uma cascata de reações envolvidas com a senescência foliar onde o gene CCGS está envolvido com a síntese de clorofilas (HUANG et al. 2017).

Em relação ao estudo das enzimas antioxidantes e PTS, foi observada interação significativa entre os fatores em estudo somente para a enzima SOD, e ao analisar a interação, somente o controle apresentou aumento da concentração dessa enzima na condição de maior disponibilidade de água (Tabela 2), neste trabalho o comportamento da enzima SOD indica que mais mecanismos de defesa poderiam estar atuando na eliminação de superóxido $\left(\mathrm{O}_{2}{ }^{-}\right)$, uma vez que essa enzima é considerada a primeira linha de defesa antioxidante das plantas (GILL et al. 2015).

Ao analisar o efeito isolado de cada nível dos fatores em estudo para APX e CAT verificamos que o tratamento $A B A+M e J A$ incrementou a concentração dessas enzimas, e para a APX os níveis de água no solo apresentaram diferença, sendo que a concentração dessa enzima foi reduzida em $28,5 \%$ na condição de $80 \%$ da CC (Tabela 3). Também verificou-se que nenhum dos fatores em estudo promoveu alteração na concentração de PTS (Tabela 4). Diferentemente da enzima SOD, as enzimas APX e CAT estão envolvidas 
na eliminação do radical peróxido de hidrogênio $\left(\mathrm{H}_{2} \mathrm{O}_{2}\right)$, e ambas apresentaram aumento na atividade, possivelmente devido ao incremento de $\mathrm{H}_{2} \mathrm{O}_{2}$, resultado similar foi observado por CAVERZAN et al. (2012) e BARBOSA et al. (2014). Tendo em vista que o tratamento que promoveu suas maiores concentrações foi o ABA+MeJA, essa resposta pode estar relacionada a capacidade que tanto o ABA como o MeJA possuem de aumentar a concentração dessas enzimas (SOARES et al. 2010, CHOUDHARY et al. 2012).

Tabela 2. Atividade da enzima Superóxido dismutase (SOD, U $\min ^{-1} \mathrm{mg}^{-1}$ de proteína) em plantas de feijão tratadas com biorreguladores em dois níveis de água no solo.

Table 2. Superoxide dismutase activity (SOD, $U \min ^{-1} \mathrm{mg}^{-1}$ of protein) in common bean leaves treated with bioregulators and subjected to two water levels in the soil.

\begin{tabular}{lcc}
\hline \multirow{2}{*}{ Tratamentos } & \multicolumn{2}{c}{ Níveis de água no solo } \\
\cline { 2 - 3 } & $60 \%$ & $50 \%$ \\
Controle & $2,8( \pm 0,28) \mathrm{aB}$ & $5,2( \pm 0,47) \mathrm{aA}$ \\
ABA & $3,1( \pm 0,75) \mathrm{aA}$ & $3,0( \pm 0,48) \mathrm{aA}$ \\
MeJA & $4,6( \pm 1,44) \mathrm{aA}$ & $2,7( \pm 0,80) \mathrm{aA}$ \\
ABA+MeJA & $2,8( \pm 0,94) \mathrm{aA}$ & $3,9( \pm 0,38) \mathrm{aA}$ \\
\hline CV $(\%)$ & & 39,93 \\
\hline
\end{tabular}

*Médias seguidas pela mesma letra minúscula na coluna ou maiúscula na linha não diferem entre si pelo teste de Tukey a $5 \%$ de probabilidade. Média ( \pm erro padrão da média).

Tabela 3. Concentração de proteínas totais solúveis (PTS, $\mathrm{mg} \mathrm{g}^{-1} \mathrm{MF}$ ), ascorbato peroxidase (APX, $\mu \mathrm{mol}$ APX $\min ^{-1} \mathrm{mg}^{-1}$ proteína) e catalase (CAT, umol CAT $\mathrm{min}^{-1} \mathrm{mg}^{-1}$ proteína) em plantas de feijão tratadas com biorreguladores em dois níveis de água no solo.

Table 3. Total soluble protein content (PTS, $\mathrm{mg} \mathrm{g}^{-1} \mathrm{FM}$ ), ascorbate peroxidase (APX, $\mu \mathrm{mol} A P X \mathrm{~min}^{-1} \mathrm{mg}^{-1}$ of protein), and catalase (CAT, $\mu \mathrm{mol} C A T \mathrm{~min}^{-1} \mathrm{mg}^{-1}$ of protein) in common bean leaves treated with bioregulators and subjected to two water levels in the soil.

\begin{tabular}{lccc}
\hline Tratamentos & PTS & APX & CAT \\
\hline Controle & $26,1( \pm 0,7) \mathrm{a}^{*}$ & $0,35( \pm 0,09) \mathrm{b}$ & $161,1( \pm 15,8) \mathrm{ab}$ \\
ABA & $27,2( \pm 0,7) \mathrm{a}$ & $0,49( \pm 0,10) \mathrm{b}$ & $194,9( \pm 36,6) \mathrm{ab}$ \\
MeJA & $26,5( \pm 1,0) \mathrm{a}$ & $0,49( \pm 0,01) \mathrm{b}$ & $98,4( \pm 26,2) \mathrm{b}$ \\
ABA+MeJA & $23,7( \pm 1,2) \mathrm{a}$ & $0,85( \pm 0,09) \mathrm{a}$ & $237,2( \pm 47,1) \mathrm{a}$ \\
\hline Níveis de água no solo & & & \\
\hline $60 \%$ & $26,5( \pm 0,5) \mathrm{a}$ & $0,63( \pm 0,07) \mathrm{a}$ & $157,1( \pm 19,9) \mathrm{a}$ \\
$80 \%$ & $25,2( \pm 0,9) \mathrm{a}$ & $0,45( \pm 0,07) \mathrm{b}$ & $188,8( \pm 32,4) \mathrm{a}$ \\
\hline CV $(\%)$ & 10,5 & 29 & 41,9 \\
\hline
\end{tabular}

${ }^{*}$ Médias seguidas pela mesma letra não diferem entre si pelo teste de Tukey a $5 \%$ de probabilidade. Média ( \pm erro padrão da média).

Tabela 4. Taxa fotossintética $\left(A, \mu \mathrm{mol} \mathrm{m} \mathrm{m}^{-2} \mathrm{~s}^{-1}\right)$ em plantas de feijão tratadas com biorreguladores em dois níveis de água no solo.

Table 4. $\mathrm{CO}_{2}$ assimilation rate $\left(A, \mu \mathrm{mol} \mathrm{m}^{-2} \mathrm{~s}^{-1}\right)$ in common bean leaves treated with bioregulators and subjected to two water levels in the soil.

\begin{tabular}{|c|c|c|c|c|}
\hline \multirow{3}{*}{ Tratamentos } & \multicolumn{2}{|c|}{34 dias após plantio (DAP) } & \multicolumn{2}{|c|}{36 dias após plantio (DAP) } \\
\hline & \multicolumn{4}{|c|}{ Níveis de água no solo } \\
\hline & $60 \%$ & $80 \%$ & $60 \%$ & $80 \%$ \\
\hline Controle & $9,7( \pm 1,1) \mathrm{cB}^{*}$ & $19,4( \pm 0,9)$ aA & $10,9( \pm 1,4) a b A$ & $12,0( \pm 2,3) \mathrm{aA}$ \\
\hline ABA & $16,7( \pm 1,8) a b A$ & $13,7( \pm 2,4 \mathrm{aA}$ & $12,6( \pm 2,1) a b A$ & $13,6( \pm 0,8)$ aA \\
\hline MJeA & $21,3( \pm 2,0) a A$ & $17,7( \pm 1,4)$ aA & $7,8( \pm 0,3) b A$ & $7,8( \pm 2,6)$ aA \\
\hline ABA+MeJA & $12,7( \pm 2,4) \mathrm{bcA}$ & $15,6( \pm 2,4)$ aA & $18,2( \pm 1,7)$ aA & $7,8( \pm 1,2) a B$ \\
\hline
\end{tabular}

${ }^{*}$ Médias seguidas pela mesma letra minúscula na coluna ou maiúscula na linha não diferem entre si pelo teste de Tukey a $5 \%$ de probabilidade. Média ( \pm erro padrão da média).

Com relação as trocas gasosas das plantas de feijoeiro, observamos que para a taxa de assimilação de $\mathrm{CO}_{2}(A)$, houve interação significativa dos fatores em estudo nos dois períodos de avaliação, não sendo observadas diferenças entre os biorreguladores na condição de $80 \%$ da CC em nenhuma das duas análises (Tabela 4). Na condição de menor disponibilidade hídrica os tratamentos MeJA e ABA incrementaram a taxa 
fotossintética das plantas de feijoeiro aos 34 DAP e o tratamento ABA+MeJA aos 36 DAP (Tabela 5). O metil jasmonato apresenta potencial regulador da taxa fotossintética das plantas quando aplicado externamente (JANOUDI \& FLORE 2003, ANJUM et al. 2011), evidenciando seu efeito inibitório em determinados processos fisiológicos nos vegetais (GIANNAKOULA et al. 2012).

No entanto nossos resultados demonstram que o MeJA incrementou as taxas fotossintéticas na primeira avaliação (Tabela 4), resultados similares foram observados em plantas de trigo submetidas a 25 $\mu \mathrm{M}$ de MeJA sob déficit hídrico, onde este biorregulador mostrou-se um atenuador déficit hídrico por promover um leve fechamento estomático e assim manter o equilíbrio hídrico da planta (MA et al. 2014). Entretanto 0 uso de jasmonatos nas plantas, em condições de estresse, são influenciadas pela concentração utilizada, estádio fenológico de aplicação e espécie estudada (AHMAD et al. 2016), esta pesquisa promoveu a reaplicação dos biorreguladores, o que acarretou em acréscimos no conteúdo do MeJA no tecido vegetal o que levou a reduções taxa fotossintética na segunda avaliação (Tabela 5), sugerindo que essas respostas estariam diretamente relacionadas com o efeito das doses proporcionadas pelas duas aplicações de biorreguladores.

Tabela 5. Condutância estomática $\left(g s, \mathrm{~mol} \mathrm{~m}^{-2} \mathrm{~s}^{-1}\right)$ em plantas de feijão tratadas com biorreguladores em dois níveis de água no solo.

Table 5. Stomatal conductance ( $\mathrm{gs}, \mathrm{mol} \mathrm{m}^{-2} \mathrm{~s}^{-1}$ ) in common bean leaves treated with bioregulators and subjected to two water levels in the soil.

\begin{tabular}{lcccc}
\hline \multirow{2}{*}{ Tratamentos } & \multicolumn{2}{c}{34 dias após plantio (DAP) } & \multicolumn{2}{c}{36 dias após plantio (DAP) } \\
\cline { 2 - 5 } & \multicolumn{2}{c}{ Níveis de água no solo } & \multicolumn{2}{c}{ Níveis de água no solo } \\
\cline { 2 - 5 } & $60 \%$ & $80 \%$ & $60 \%$ & $80 \%$ \\
\hline Controle & $0,29( \pm 0,059) \mathrm{aA}$ & $0,28( \pm 0,048) \mathrm{aA}$ & $0,12( \pm 0,02) \mathrm{aB}$ & $0,30( \pm 0,03) \mathrm{aA}$ \\
ABA & $0,30( \pm 0,045) \mathrm{aA}$ & $0,23( \pm 0,065) \mathrm{aA}$ & $0,2( \pm 0,01) \mathrm{aA}$ & $0,12( \pm 0,01) \mathrm{bcB}$ \\
MJeA & $0,25( \pm 0,053) \mathrm{aA}$ & $0,27( \pm 0,033) \mathrm{aA}$ & $0,15( \pm 0,03) \mathrm{aA}$ & $0,10( \pm 0,01) \mathrm{cA}$ \\
ABA+MeJA & $0,33( \pm 0,056) \mathrm{aA}$ & $0,21( \pm 0,071) \mathrm{aA}$ & $0,17( \pm 0,04) \mathrm{aA}$ & $0,20( \pm 0,02) \mathrm{abA}$ \\
\hline
\end{tabular}

$\mathrm{CV}(\%)$ 29,6

${ }^{*}$ Médias seguidas pela mesma letra minúscula na coluna ou maiúscula na linha não diferem entre si pelo teste de Tukey a $5 \%$ de probabilidade. Média ( \pm erro padrão da média).

O tratamento com ABA não diferiu do MeJA na primeira avaliação (Tabela 5), McLAREN \& SMITH (1976) estudando o efeito da aplicação externa de ácido abcísico em Limna minor L. reportam que após a aplicação externa de ácido abscísico há aumento da taxa fotossintética e, em seguida, ocorre o declínio desta, esse comportamento pode estar envolvido com a acumulação de carboidratos na planta, e sua ação regulatório na fotossíntese. Já aplicações de metil jasmonato em soja, sob déficit hídrico, durante o florescimento, apresentaram reduções de $11,3 \%$ na $A$, resultado motivado pelo fechamento estomático (ANJUM et al. 2011). Mesmo fenômeno foi observado para o tratamento MeJA durante avaliação das trocas gasosas aos 36 DAP (Tabela 4).

Os biorreguladores não apresentaram influência em gs na condição de menor disponibilidade hídrica, no entanto o controle apresentou aumento de $60 \%$ da gs quando comparado o nível de maior com o de menor disponibilidade de água no solo, sendo observado o contrário para o ABA, que apresentou redução de $40 \%$ na gs realizando a mesma comparação (Tabela 5). Ainda, no nível de maior disponibilidade hídrica os biorreguladores MeJA e ABA promoveram redução da gs (Tabela 5). Aos 34 DAP nem os tratamentos nem a interação dos fatores foram significativas. O ABA e o MeJA são duas moléculas que possuem forte influência no fechamento estomático (SUHITA et al. 2003), sendo este fenômeno muito bem reportado na literatura (JANOUDI \& FLORE 2003, ANJUM et al. 2011, KOBAYAKAWA \& IMAI 2012), mesmo em condições de boa disponibilidade hídrica a condutância estomática pode ser afetada pelo metil jasmonato, uma vez que este biorregulador regula negativamente a abertura dos estômatos em 7,56\%, nessas condições (ANJUM et al. 2011). Os menores valores no nível de maior disponibilidade hídrica promovidos pelos tratamentos MeJA e ABA aos 36 DAP (Tabela 5), estão relacionados com a ação destes biorreguladores na regulação da abertura dos estômatos.

Os dados da concentração interna de $\mathrm{CO}_{2}(C l)$, aos $34 \mathrm{DAP}$, apresentaram interação significativa entre hormônio e nível de água, sendo que sob condições de melhor disponibilidade hídrica não observamos diferenças no fator biorreguladores (Tabela 6). Os tratamentos MeJA e ABA promoveram redução da Ci na condição de $60 \%$ da CC e ainda quando comparados os níveis de água no solo, o controle e o tratamento ABA+MeJA apresentaram maior Ci nessa mesma disponibilidade hídrica. Em contrapartida aos 36 DAP somente as diferentes disponibilidades hídricas no solo influenciaram a variável $C i$, que 
apresentou incremento de 35,9\% na condição de melhor disponibilidade hídrica quando comparada a de menor água disponível no solo (Tabela 6).

Tabela 6. Concentração interna de gás carbônico $(C i, \mathrm{~Pa})$ em plantas de feijão tratadas com biorreguladores em dois níveis de água no solo.

Table 6. Internal $\mathrm{CO}_{2}$ concentration ( $\mathrm{Ci}, \mathrm{Pa}$ ) in common bean leaves treated with bioregulators and subjected to two water levels in the soil.

\begin{tabular}{|c|c|c|}
\hline \multirow{3}{*}{ Tratamentos } & \multicolumn{2}{|c|}{34 dias após plantio (DAP) } \\
\hline & \multicolumn{2}{|c|}{ Níveis de água no solo } \\
\hline & $60 \%$ & $80 \%$ \\
\hline Controle & $35,4( \pm 0,9) a A^{*}$ & $28,0( \pm 1,0) \mathrm{aB}$ \\
\hline $\mathrm{ABA}$ & $31,0( \pm 2,5)$ abA & $28,5( \pm 2,1)$ aA \\
\hline MeJA & $24,7( \pm 0,8) b A$ & $26,7( \pm 1,1)$ aA \\
\hline $\mathrm{ABA}+\mathrm{MeJA}$ & $33,9( \pm 2,2)$ aA & $25,0( \pm 1,6)$ aB \\
\hline \multirow[t]{2}{*}{$\mathrm{CV}(\%)$} & \multicolumn{2}{|c|}{12,8} \\
\hline & \multicolumn{2}{|c|}{36 dias após plantio (DAP) } \\
\hline Biorreguladores & \multicolumn{2}{|c|}{$\mathrm{Ci}$} \\
\hline Controle & \multicolumn{2}{|c|}{$22,7( \pm 2,0) a$} \\
\hline ABA & \multicolumn{2}{|c|}{$26,1( \pm 3,6) a$} \\
\hline MeJA & \multicolumn{2}{|c|}{$25,5( \pm 1,2) a$} \\
\hline $\mathrm{ABA}+\mathrm{MeJA}$ & \multicolumn{2}{|c|}{$31,6( \pm 3,5) a$} \\
\hline Níveis de água no solo & \multicolumn{2}{|c|}{$\mathrm{Ci}$} \\
\hline $60 \%$ & \multicolumn{2}{|c|}{$20,7( \pm 1,4) b$} \\
\hline $80 \%$ & \multicolumn{2}{|c|}{$32,3( \pm 3,7) \mathrm{a}$} \\
\hline $\mathrm{CV}(\%)$ & \multicolumn{2}{|c|}{40,5} \\
\hline
\end{tabular}

*Médias seguidas pela mesma letra minúscula na coluna ou maiúscula na linha não diferem entre si pelo teste de Tukey a $5 \%$ de probabilidade. Média ( \pm erro padrão da média).

Incrementos na disponibilidade hídrica possuem relação linear com o aumento da concentração interna de $\mathrm{CO}_{2}$ (SILVA et al. 2015), esse comportamento foi observado na segunda avaliação das trocas gasosas (Tabela 6), uma vez que as plantas quando colocadas em melhores condições hídricas aumentam a condutância estomática e por consequência o aporte de $\mathrm{CO}_{2}$ (OLIVEIRA et al. 2005). Uma possível explicação para a redução de Ci causada pelos tratamentos MeJA e ABA na primeira avaliação (Tabela 6) é o envolvimento do metil jasmonato e do ácido abscísico no fechamento estomático, que leva ao menor aporte de moléculas de $\mathrm{CO}_{2}$ (SUHITA et al. 2003).

Estudando a transpiração nenhuma diferença foi promovida na variável $E$ aos 34 DAP enquanto que na segunda avaliação das trocas gasosas foi observada interação entre biorregulador e nível de água no solo, no entanto somente o controle aumentou a transpiração das plantas à medida que se elevou o nível de água no solo (Tabela 7), fato determinado pela restrição de água que caracteriza um ambiente com estresse hídrico (OHASHI et al. 2006). Os resultados deste trabalho para a $E$ na segunda avaliação das trocas gasosas (Tabela 7) refletem exatamente as observações previamente discutidas, no menor nível de água no solo, uma vez que o controle apresentou este comportamento quando submetido à condição de menor disponibilidade hídrica.

Tabela 7. Transpiração $\left(E, \mathrm{~mol} \mathrm{H}_{2} \mathrm{O} \mathrm{m} \mathrm{m}^{-2} \mathrm{~s}^{-1}\right)$ em plantas de feijão tratadas com biorreguladores em dois níveis de água no solo.

Table 7. Transpiration rate $\left(\mathrm{E}, \mathrm{mol} \mathrm{H}_{2} \mathrm{O} \mathrm{m} \mathrm{m}^{-2}\right)$ in common bean leaves treated with bioregulators and subjected to two water levels in the soil.

\begin{tabular}{lcc}
\hline & \multicolumn{2}{c}{36 dias após plantio (DAP) } \\
\hline \multirow{2}{*}{ Tratamentos } & \multicolumn{2}{c}{ Níveis de água no solo } \\
\cline { 2 - 3 } & $60 \%$ & $80 \%$ \\
\hline Controle & $2,0( \pm 0,4) \mathrm{aB}^{*}$ & $5,0( \pm 1,8) \mathrm{aA}$ \\
ABA & $4,8( \pm 0,4) \mathrm{aA}$ & $2,3( \pm 0,8) \mathrm{aA}$ \\
MeJA & $4,3( \pm 0,7) \mathrm{aA}$ & $3,0( \pm 0,7) \mathrm{aA}$ \\
ABA+MeJA & $4,1( \pm 1,1) \mathrm{aA}$ & $4,0( \pm 0,8) \mathrm{aA}$ \\
\hline CV $(\%)$ & \multicolumn{3}{c}{}
\end{tabular}

*Médias seguidas pela mesma letra minúscula na coluna ou maiúscula na linha não diferem entre si pelo teste de Tukey a $5 \%$ de probabilidade. Média ( \pm erro padrão da média). 
Por fim, analisando a influência dos biorreguladores e dos níveis de água no solo no $A / E$ foram observadas interações significativas entre os fatores em estudo em ambos os dias de análise (Tabela 8). Os biorreguladores não promoveram nenhum efeito no $A / E$ na condição de melhor nível de água no solo em nenhuma das duas avaliações. No entanto os tratamentos MeJA e ABA aos 34 DAP, assim como o $A B A+M e J A$ aos 36 DAP, promoveram o incremento da variável $A / E$ na condição de $60 \%$ da CC. Além disso, o tratamento $A B A+M e J A$ apresentou maior $A / E$ no melhor nível de água no solo na primeira avaliação, sendo o contrário para a segunda análise, onde o controle e ABA+MeJA apresentaram essa resposta na condição de $60 \%$ da CC (Tabela 8). Devido aos tratamentos não apresentarem diferença para a variável $E \mathrm{e}$ o tratamento com MeJA ter atingido o maior valor de $A$, o tratamento MeJA alcançou o melhor resultado de $A / E$ na primeira avaliação, isso significa que a planta está perdendo menos moléculas de água por molécula de $\mathrm{CO}_{2}$ aportada (WEBBER et al. 2006). Uma interessante resposta das plantas é aumentar a eficiência do uso da água quando submetidas ao estresse hídrico (ZHAO et al. 2017), essa resposta foi observada na segunda avaliação para o tratamento controle (Tabela 8).

Tabela 8. Eficiência do uso de água $(A / E)$ em plantas de feijão tratadas com biorreguladores em dois níveis de água no solo.

Table 8. Water use efficiency rate $(A / E)$ in common bean leaves treated with bioregulators and subjected to two water levels in the soil.

\begin{tabular}{|c|c|c|c|c|}
\hline \multirow{3}{*}{ Tratamentos } & \multicolumn{2}{|c|}{34 dias após plantio (DAP) } & \multicolumn{2}{|c|}{36 dias após plantio (DAP) } \\
\hline & \multicolumn{4}{|c|}{ Níveis de água no solo } \\
\hline & $60 \%$ & $80 \%$ & $60 \%$ & $80 \%$ \\
\hline Controle & $2,4( \pm 0,3) b A^{*}$ & $3,8( \pm 0,3)$ aA & $5,9( \pm 0,7)$ aA & $2,4( \pm 1,1) \mathrm{aB}$ \\
\hline ABA & $3,4( \pm 0,6)$ abA & $3,8( \pm 0,6)$ aA & $2,8( \pm 1,1)$ bcA & $4,1( \pm 2,8)$ aA \\
\hline MeJa & $4,8( \pm 0,3)$ aA & $4,0( \pm 0,4) \mathrm{aA}$ & $2,0( \pm 0,4) \mathrm{cA}$ & $2,5( \pm 0,4)$ aA \\
\hline $\mathrm{ABA}+\mathrm{MeJa}$ & $2,6( \pm 0,5) b B$ & $4,9( \pm 1,0)$ aA & $5,0( \pm 0,7)$ abA & $2,1( \pm 0,3)$ aB \\
\hline $\mathrm{CV}(\%)$ & & & & \\
\hline
\end{tabular}

*Médias seguidas pela mesma letra minúscula na coluna ou maiúscula na linha não diferem entre si pelo teste de Tukey a $5 \%$ de probabilidade. Média ( \pm erro padrão da média).

Os biorreguladores e os níveis de água no solo não apresentaram interação significativa em nenhuma das variáveis biométricas estudadas, no entanto avaliando-se o desdobramento para cada nível dos fatores separadamente, as variáveis AP e BF Planta ${ }^{-1}$ apresentaram diferença entre as duas disponibilidades hídricas, em que à medida que se aumentava a disponibilidade hídrica as duas variáveis também aumentavam. Esse aumento foi de $11,7 \%$ e $35 \%$, para AP e BF Planta ${ }^{-1}$, respectivamente (Tabela 9).

Tabela 9. Altura de plantas (AP) e número de botões florais por planta (BF) em plantas de feijão tratadas com biorreguladores em dois níveis de água no solo.

Table 9. Plant height (PH) and flower bud per plant (FB) in common bean leaves treated with bioregulators and subjected to two water levels in the soil.

\begin{tabular}{lcc}
\hline Tratamentos & $\mathrm{AP}(\mathrm{cm})$ & $\mathrm{BF}\left(\mathrm{Planta}^{-1}\right)$ \\
\hline Controle & $44,2( \pm 1,8) \mathrm{a}^{*}$ & $7,4( \pm 1,0) \mathrm{a}$ \\
ABA & $45,2( \pm 1,8) \mathrm{a}$ & $7,4( \pm 0,9) \mathrm{a}$ \\
MeJA & $49,3( \pm 1,9) \mathrm{a}$ & $8,7( \pm 0,8) \mathrm{a}$ \\
ABA+MeJA & $50,5( \pm 4,0) \mathrm{a}$ & $7,6( \pm 0,8) \mathrm{a}$ \\
\hline Níveis de água no solo & $\mathrm{AP}(\mathrm{cm})$ & $\mathrm{BF}\left(\mathrm{Planta}^{-1}\right)$ \\
\hline $60 \%$ & $44,35( \pm 1,4) \mathrm{b}$ & $6,10( \pm 0,4) \mathrm{b}$ \\
$80 \%$ & $50,25( \pm 2,0) \mathrm{a}$ & $9,45( \pm 0,6) \mathrm{a}$ \\
\hline CV $(\%)$ & 16,5 & 28,6 \\
\hline
\end{tabular}

${ }^{\star}$ Médias seguidas pela mesma letra não diferem entre si pelo teste de Tukey a $5 \%$ de probabilidade. Média ( \pm erro padrão da média).

Considerando as variáveis biométricas do estudo, a altura de plantas adequada no feijoeiro é de extrema importância, pois interfere diretamente na altura de inserção da primeira vagem e no acamamento das plantas, que por sua vez interferem na produtividade final (HORN et al. 2000). Desta forma, é importante que as plantas possuam disponibilidade adequada de água para atingir uma altura final que promova os benefícios na produtividade que essa característica pode proporcionar. O estresse hídrico afeta drasticamente os processos de reprodução em grandes culturas, e os danos causados impedem ganhos na 
fixação floral (BARNABÁS et al. 2008). Este trabalho reflete essa informação, pois onde havia melhor disponibilidade de água para as plantas ( $80 \%$ da capacidade de campo) contabilizaram-se o maior número de botões florais (Tabela 9).

Os biorreguladores, em geral, não proporcionaram respostas na condição de melhor disponibilidade hídrica. É possível que essas observações tenham ocorrido pelo fato dos biorreguladores ácido abscísico e metil jasmonato estarem envolvidos com distintas respostas a estresses nas plantas (AHMAD et al. 2016, $\mathrm{SAH}$ et al. 2016), onde as respostas fisiológicas observadas se relacionam à tolerância das plantas de feijoeiro as condições hídricas de cultivo e a performance do feijoeiro varia de acordo com sua adaptabilidade nas regiões de cultivo (SINGH 1989).

\section{CONCLUSÃO}

Os biorreguladores, ácido abscísico e metil jasmonato, são alternativas viáveis para a mitigação do estresse hídrico em feijoeiro, por beneficiar o status hídrico nos tecidos foliares do feijoeiro, aprimorar os mecanismos de defesa enzimáticos e beneficiar as respostas de trocas gasosas em condição de $60 \%$ da capacidade de campo do solo.

O nível de água no solo é fator predominante para o proeminente desenvolvimento da cultura, e sobrepõe o fator biorregulador na cultura do feijoeiro, e solos com $80 \%$ da capacidade de campo representam a condição adequada para o cultivo adequado do feijoeiro cv. BRS Pérola.

\section{AGRADECIMENTOS}

A Fundação de Amparo à Pesquisa de Minas Gerais (FAPEMIG) pelo financiamento deste projeto (Processo: APQ-02110-15) e apoio da Coordenação de Aperfeiçoamento de Pessoal de Nível Superior Brasil (CAPES) - Código de Financiamento 001.

\section{REFERÊNCIAS}

AHMAD P et al. 2016. Jasmonates: Multifunctional Roles in Stress Tolerance. Frontiers in Plant Science 7: 1-15.

ANDERSON MD et al. 1995. Changes in isozyme profiles of catalase, peroxidase, and glutathione reductase during acclimation to chilling in mesocotyl of maize seedlings. Plant Physiology 109: 1247-1257.

ANJUM SA et al. 2011. Effect of exogenous methyl jasmonate on growth, gas exchange and chlorophyll contents of soybean subjected to drought. African Journal of Biotechnology 10: 9640-9646.

BARBOSA MR et al. 2014. Geração e desintoxicação enzimática de espécies reativas de oxigênio em plantas. Ciência Rural 44: 453-460.

BARI R \& JONES JDG. 2009. Role of plant hormones in plant defence responses. Plant Molecular and Biolgy 69:473488.

BARICKMAN TC et al. 2014. Abscisic acid increases carotenoid and chlorophyll concentrations in leaves and fruit of two tomato genotypes. Journal of the American Society for Horticultural Science 139: 261-266.

BARNABÁS B et al. 2008. The effect of drought and heat stress on reproductive processes in cereals. Plant, Cell and Environment 31: 11-38.

BEAUCHAMP C \& FRIDOVICH I. 1971. Superoxide dismutase: improved assays and an assay applicable to acrylamide gels. Analytical Biochemistry 44: 276-287.

BRADFORD MM. 1976. Rapid and sensitive method for quantitation of microgram quantities of protein utilizing principle of protein-dye binding. Analytical Biochemistry 72: 248-254.

CAVERZAN A et al. 2012. Plant responses to stresses: Role of ascorbate peroxidase in the antioxidant protection. Genetics and Molecular Biology 35: 1011-1019.

CHOUDHARY R et al. 2012. Effect of abscisic acid and hydrogen peroxide on antioxidant enzymes in Syzygium cumini plant. Journal of Food Science and Technology 49: 649-652.

FERNANDES B \& SYKES DJ. 1968. Capacidade de campo e retenção de água em três solos de Minas Gerais. Revista Ceres 15: 1-39.

GIANNAKOULA AE et al. 2012. The effects of plant growth regulators on growth, yield, and phenolic profile of lentil plants. Journal of Food Composition and Analysis 28: 46-53.

GIANNOPOLITIS CN \& RIES SK. 1977. Superoxide dismutases. I. Occurrence in higher plants. Plant Physiology 59: 309-314.

GILL SS et al. 2015. Superoxide dismutase-mentor of abiotic stress tolerance in crop plants. Environmental Science and Pollution Research 22: 10375-10394.

GRAFTON RQ et al. 2015. Food and water gaps to 2050: preliminary results from the global food and water system (GFWS) platform. Food Security 7: 209-220.

HAVIR EA \& MCHALE NA. 1987. Biochemical and developmental characterization of multiple forms of catalase in tobacco leaves. Plant Physiology 84: 450-455.

HORN FL et al. 2000. Avaliação de espaçamentos e populações de plantas de feijão visando à colheita mecanizada 
direta. Pesquisa Agropecuária Brasileira 35: 41-46.

HUANG $\mathrm{H}$ et al. 2017. Jasmonate action in plant growth and development. Journal of Experimental Botany 68: 13491359.

JALEEL CA. et al. 2009. Drought stress in plants: a review on morphological characteristics and pigments composition. International Journal of Agriculture and Biology 11: 100-105.

JANOUDI A \& FLORE JA. 2003. Effects of multiple applications of methyl jasmonate on fruit ripening, leaf gas exchange and vegetative growth in fruit trees. Journal of Horticultural Science \& Biotechnology 78: 793-797.

KHADRI $\mathrm{M}$ et al. 2006. Alleviation of salt stress in common bean (Phaseolus vulgaris) by exogenous abscisic Acid supply. Journal of Plant Growth Regulation 25: 110-119.

KOBAYAKAWA H \& IMAI K. 2012. Methyl jasmonate affects $\mathrm{O}_{3}$-inhibition of photosynthesis and ascorbic acid content in paddy rice grown at different $\mathrm{CO}_{2}$ concentrations. Environmental Control in Biology 50: 335-345.

LANNA AC et al. 2016. Physiological characterization of common bean (Phaseolus vulgaris L.) genotypes, water-stress induced with contrasting response towards drought. Australian Journal of Crop Science 10: 1-6.

LICHTENTHALER H \& WELLBURN A. 1993. Determinations of total carotenoids and chlorophylls a and $b$ of leaf extracts in different solvents. Biochemical Society Transactions 11: 591-592.

MA C et al. 2014. Photosynthetic responses of wheat (Triticum aestivum L.) to combined effects of drought and exogenous methyl jasmonate. Photosynthetica 52: 377-385.

MACEDO WR et al. 2013. Unravelling the physiologic and metabolic action of thiamethoxan on rice plants. Pesticide Biochemistry and Physiology 107: 244-249.

MCLAREN JS \& SMITH H. 1976. The effect of abscisic acid on growth, photosynthetic rate and carbohydrate metabolism in Lemina minor. New Phytologist 76: 11-20.

MUÑOZ-PEREA CG et al. 2006. Selection for drought resistence in dry bean landraces and cultivars. Crop Science 46: 2111-2120.

NAKANO Y \& ASADA K. 1981. Hydrogen peroxide is scavenged by ascorbate specific peroxidase in spinach chloroplasts. Plant and Cell Physiology 22: 867-880.

OHASHI $Y$ et al. 2006. Effects of drought stress on photosynthetic gas exchange, chlorophyll fluorescence and stem diameter of soybean plants. Biologia Plantarum 50: 138-141.

OLIVEIRA AD et al. 2005. Condutância estomática como indicador de estresse hídrico em feijão. Engenharia Agrícola 25: 86-95.

OLIVEIRA MB et al. 2015. Exogenous application of methyl jasmonate induces a defense response and resistance against Sclerotinia sclerotiorum in dry bean plants. Journal of Plant Physiology 182: 13-22.

OSTER $U$ et al. 2000. Cloning and functional expression of the gene encoding the key enzyme for chlorophyll $b$ biosynthesis (CAO) from Arabidopsis thaliana. Plant Journal 21: 305-310.

PAVLOVIĆ D et al. 2014. Chlorophyll as a measure of plant health: Agroecological aspects. Journal Pesticides and Phytomedicine 29: 21-34.

RAHMAN MH. 2016. Exploring sustainability to feed the world in 2050. Journal of Food Microbiology 1: 7-16.

RATNAKUMAR P et al. 2016. Can plant bio-regulators minimize crop productivity losses caused by drought, salinity and heat stress? An integrated review. Journal of Applied Botany and Food Quality 89: 113-125.

SAH SK et al. 2016. Abscisic acid and abiotic stress tolerance in crop plants. Frontiers in Plant Science 7: 571.

SANKAR B et al. 2013. Photosynthetic pigment content alterations in Arachis hypogaea $L$. in relation to varied irrigation levels with growth hormone and triazoles. Journal of Ecobiotechnology 5: 7-13.

SILVA FG et al. 2015. Trocas gasosas e fluorescência da clorofila em plantas de berinjela sob lâminas de irrigação. Revista Brasileira de Engenharia Agrícola e Ambiental 19: 946-952.

SINGH SP. 1989. Patterns of Variation in Cultivated Common Bean (Phaseolus vulgaris, Fabaceae). Economic Botany 43: 39-57.

SOARES AMS et al. 2010. T. Effect of methyl jasmonate on antioxidative enzyme activities and on the contents of ROS and $\mathrm{H}_{2} \mathrm{O}_{2}$ in Ricinus communis leaves. Brazilian Journal of Plant Physiology 22: 151-158.

SUHITA D et al. 2003. Different signaling pathways involved during the suppression of stomatal opening by methyl jasmonate or abscisic acid. Plant Science 164: 481-488.

WASTERNACK C \& HAUSE B. 2002. Jasmonates and octadecanoids: signals in plant stress responses and development. Progress in Nucleic Acid Research and Molecular Biology 72: 165-221.

WEBBER HA et al. 2006. Water use efficiency of common bean and green gram grown using alternate furrow and deficit irrigation. Agricultural Water Management 86: 259-268.

WITHAM FH et al. 1971. Experiments in Plant Physiology. New York: D. Van Nostrand Company. p 55-58.

YANG Z et al. 2016. Leveraging abscisic acid receptors for efficient water use in Arabidopsis. Proceedings of the National Academy of Sciences 113: 6791-6796.

ZHAO N et al. 2017. Interaction of $\mathrm{CO}_{2}$ concentrations and water stress in semiarid plants causes diverging response in instantaneous water use efficiency and carbon isotope composition. Biogeosciences 14: 3431-3444.

ZLATEV Z \& LIDON FC. 2012. An overview on drought induced changes in plant growth, water relations and photosynthesis. Emirates Journal of Food and Agriculture 24: 57-72. 